\title{
Decrease in Brain Glucose in Anoxia in Spite of Elevated Plasma Glucose Levels
}

\author{
Jean Holowach-Thurston ${ }^{[14]}$, Righard E. Hauhart, Elizabeth M. Jones, \\ Maria G. Ikossi, and R. Wendell Pierce \\ Edward Mallinckrodt Department of Pediatrics, Division of Neurology, St. Louis Children's Hospital, \\ Washington University School of Medicine, St. Louis, Missouri, USA
}

\begin{abstract}
Extract
Anoxia was produced in 34 mice less than $12 \mathrm{hr}$ of age by exposure to $\mathrm{N}_{2}$ at $37^{\circ}\left(\mathrm{P}_{\mathrm{O}_{2}}\right.$ less than $5 \mathrm{~mm} \mathrm{Hg}$ ). Although brain glucose levels fell from the normal value of $0.60 \pm 0.14 \mathrm{mmol} / \mathrm{kg}$ to $0.22 \pm 0.04 \mathrm{mmol} / \mathrm{kg}$ after $6 \mathrm{~min}$ of anoxia, in the livers of the same animals there was a fourfold increase in glucose concentration from $2.61 \pm 0.28 \mathrm{mmol} / \mathrm{kg}$ to $10.45 \pm 0.45$. In 22 other animals of the same age plasma glucose levels increased from $3.04 \pm 0.03 \mathrm{~mm}$ to $5.56 \pm 1.09 \mathrm{~mm}$ during this interval of anoxia. Further studies concerned the mechanism of this unexpected independence of blood and brain glucose values during anoxia.

During the $6 \mathrm{~min}$ of anoxia brain lactate increased $7.49 \mathrm{mmol} / \mathrm{kg}$. This increase is more than twice that accounted for by the total decrease in brain glucose and glycogen. One explanation for this finding is an increased uptake of glucose from the blood by the brain. If so, the rate of glucose influx is almost 5 times that reported for newborn mice with an adequate $\mathrm{O}_{2}$ supply. Another possibility is a transport or diffusion of lactate from the blood to the brain. However, a study of the effect of lactate administration on levels of lactate in plasma and brain of 17 newborn mice suggests that permeation of the blood-brain barrier to lactate is a less likely explanation. Inasmuch as glycolysis increases 10 -fold in ischemic brain of the neonatal mouse, it appears that brain glucose decreases in these animals because the demand for glucose during anoxia exceeds the supply.
\end{abstract}

\section{Speculation}

In experimental animals levels of glucose in plasma are not always an accurate reflection of glucose levels in the brain. This is the case in anesthesia, after chronic administration of hydrocortisone, and in acute salicylate poisoning. The present study is another example of this paradox. During 6 min of anoxia, brain glucose in newborn mice fell $72 \%$ despite a doubling of the concentration of glucose in plasma. Because it is generally accepted that a decrease in the brain glucose reserve is potentially serious, it is important to recognize that a normal or even increased blood sugar need not signify adequate cerebral glucose levels. Furthermore, there is some evidence to suggest that, under these circumstances, the administration of glucose may be life saving. 


\section{Introduction}

Under normal conditions levels of glucose in the brain are proportional to the concentration of glucose in the blood. Insulin-induced hypoglycemia is associated with a reduction in the cencentration of glucose in the brain [8] and administration of glucose to normal animals produces an elevation of the concentration of glucose in the brain [10]. However, such parallelism is not universal. Increased levels of brain glucose with normal serum (or plasma) glucose levels are seen during anesthesia produced by phenobarbital and chloroform [10] and in nonanesthetized mice after chronic administration of hydrocortisone [6]. The reverse situation, an extreme decrease in brain glucose concentration with normal plasma (and liver) glucose levels is even less widely appreciated. We have previously reported such findings in acute experimental salicylate intoxication [7]. Thirty minutes after intraperitoneal injection of salicylate, brain glucose was reduced $75 \%$ despite the fact that plasma glucose levels in these same animals were not reduced. A study of the effects of oxygen deprivation on levels of glucose in brain, blood, and liver reveals that anoxia induces another example of this unexpected paradox. The findings stress the fact that the supply of glucose to the brain may be inadequate even when blood glucose levels are normal.

\section{Methods}

\section{Preparation of Animals}

The effects of anoxia on selected brain metabolites were studied in six litters of normal white mice less than $12 \mathrm{hr}$ of age (total 34 animals). Mice of this age were selected because of our clinical interest in anoxia of the neonate. Anoxia was produced by exposure of the animals to an atmosphere of nitrogen gas at $37^{\circ}$. The pressure of oxygen was monitored throughout the procedure with a Beckman oxygen electrode and maintained at less than $5 \mathrm{~mm} \mathrm{Hg}$.

The permeability of the blood-brain barrier to lactate was studied in two litters of normal mice less than $24 \mathrm{hr}$ of age (total 17 animals). Mice received subcutaneous injections of $60 \mathrm{ml} / \mathrm{kg} 0.3 \mathrm{M} \mathrm{Na}$-lactate or $0.3 \mathrm{M}$ $\mathrm{NaCl}(18 \mathrm{mmol} / \mathrm{kg})$.

At the desired intervals of anoxia or after lactate injection, the mice were killed by quick freezing in liquid nitrogen. For measurement of metabolite levels in the blood and brain of the same animals, the head was amputated directly into liquid nitrogen and blood was collected from the severed neck vessels in heparinized capillary tubes.

\section{Preparation of Blood and Tissue Extracts and Methods of Assay for Metabolites}

Before dissection, all tissues were kept at $-80^{\circ}$. The brains and livers of the frozen animals were dissected with sharp chisels in a cryostat at $-35^{\circ}$ and tissue samples were powdered and weighed in a cold room at $-23^{\circ}$. Tissue extracts were prepared according to the procedure of Lowry et al. [9] and were stored at $-80^{\circ}$ until the time of assay.

All metabolites were measured fluorometrically by specific enzymic methods. ATP, phosphocreatine, and glucose were assayed by the methods of Lowry et al. [9]. Lactate and glycogen were measured by the methods of Gatfield et al. [2]. For the determination of the concentrations of glucose and/or lactate in the blood, samples of heparinized plasma were added to a 10-20-fold volume of $0.5 \mathrm{M}$ perchloric acid and centrifuged at $4^{\circ}$. The supernatant fluid was removed and stored at $-80^{\circ}$ until the time of assay. The addition of aliquots of the perchloric acid extracts in the volume required for assay did not produce a change in the $\mathrm{pH}$ of the reagent buffer or affect the complete recovery of standards. Therefore, no preliminary neutralization of the extracts was made.

\section{Results}

\section{Changes in Metabolite Levels in Brain during Anoxia}

The effect of anoxia on glucose levels in the brain, liver, and plasma of newborn mice is shown in Fig. 1 . Values in normal animals are shown at zero time. It is interesting that in newborn mice the plasma glucose is one-half that in animals 3-16 day's of age [4]. As expected, the concentration of glucose in the liver was similar to the plasma value. Since the brain glucose concentration was also about one-half that in older animals $[1,2,8]$, the liver (or plasma) to brain glucose ratio was $5 / 1$, as in adults [10].

During the first minute of anoxia there was little change in brain glucose (the 0.5-, 1-, and 2-min levels did not differ significantly from the zero time value, at each interval, $P>0.258$ ). A similar delay in glucose utilization by the brain of the newborn mouse is seen during ischemia produced by decapitation [5]. After the initial lag glucose fell to $28 \%$ at $6 \mathrm{~min}(P$ 0.023).

The effect of anoxia on levels of ATP, P-creatine, and glycogen in the brains of these animals is shown in 


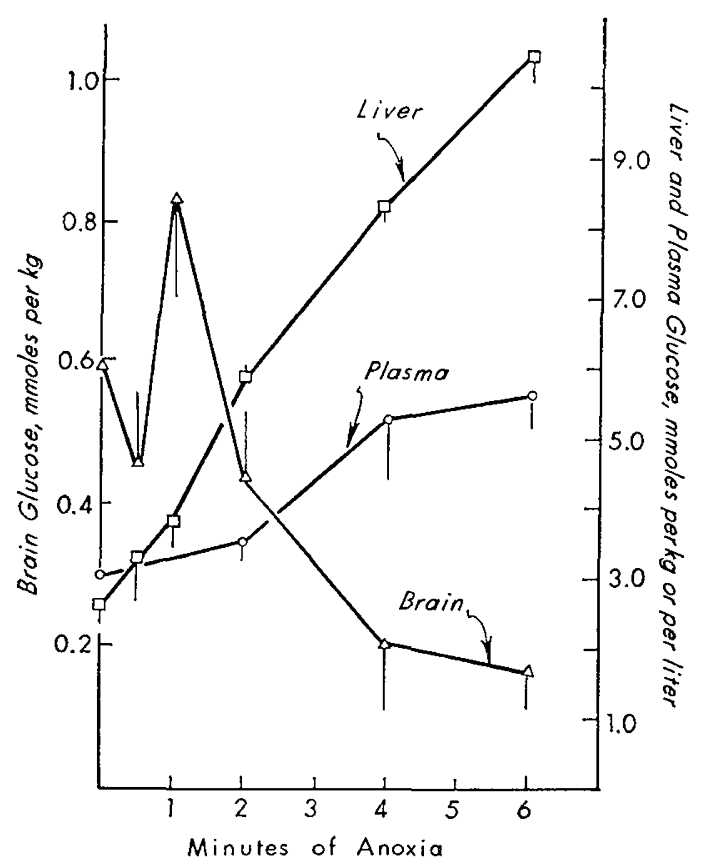

Fig. 1. Concentrations of glucose in the brain, liver, and plasma of newborn mice at intervals after anoxia $\left(\mathrm{N}_{2}\right)$. Each value is the mean of values for four-seven animals. In this and in Figures 2 and 3 , vertical lines represent \pm 1 SE. Brain and liver values are from the same animal ( 34 mice). The effect of anoxia on plasma glucose was determined in 22 other neonatal mice under similar experimental conditions.

Fig. 2. The control levels of these energy-yielding metabolites were similar to those reported earlier in newborn mice [5]. After 6 min of anoxia, brain ATP levels were reduced $30 \%$, P-creatine $86 \%$, and glycogen $40 \%$. Each of the 6-min levels was significantly reduced from the respective control value at $P<0.001$.

Brain lactate rose from the zero time value of $1.49 \pm$ 0.22 to $8.98 \pm 0.54 \mathrm{mmol} / \mathrm{kg}$. (Fig. 3). This increase, $7.49 \mathrm{mmol} / \mathrm{kg}$, is equivalent to $3.74 \mathrm{mmol} / \mathrm{kg}$ hexose. However, the total decrease of glucose and glycogen in brain over the same interval was less than one-half this amount, only $1.84 \mathrm{mmol} / \mathrm{kg}$. This finding is compatible with a net uptake of glucose from the blood by the brain. If so, the glucose uptake during anoxia occurred at an average rate of $0.33 \mathrm{mmol} / \mathrm{kg} / \mathrm{min}$, almost 5 times the flux rate calculated for newborn animals with an adequate $0_{2}$ supply [5].

\section{Permeability of Blood-Brain Barrier to Lactate}

Another explanation for the excess accumulation of lactate in the brain might be that lactate was transferred from the blood to the brain. To test this possibility we investigated the permeability of the blood-

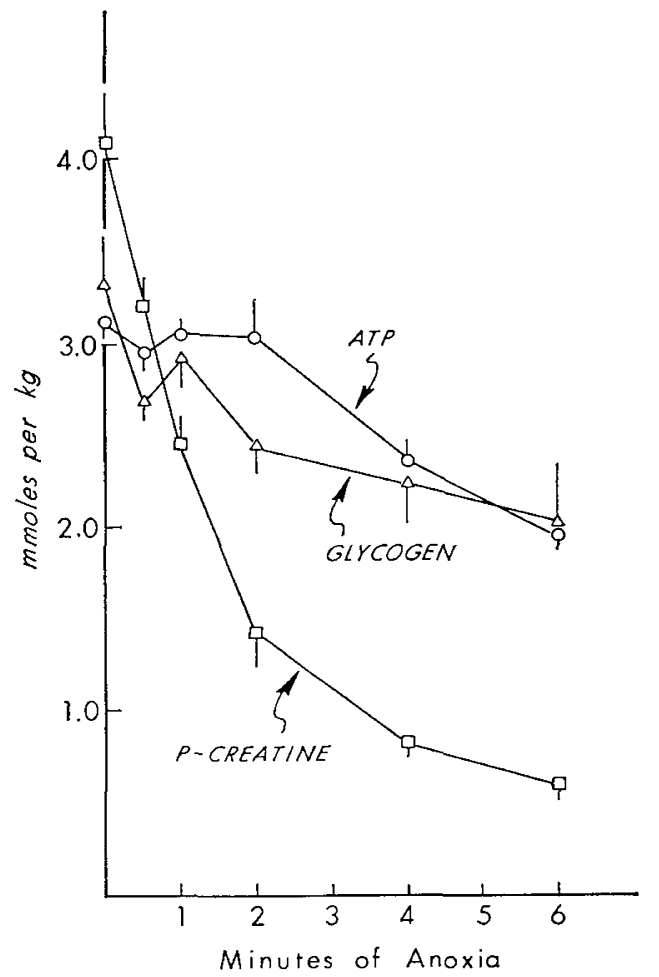

Fig. 2. Concentrations of ATP, P-creatine, and glycogen at intervals after anoxia $\left(\mathrm{N}_{2}\right)$ in the brains of animals of Figure 1. Values are given as the mean. Glycogen levels are reported as glucose equivalents.

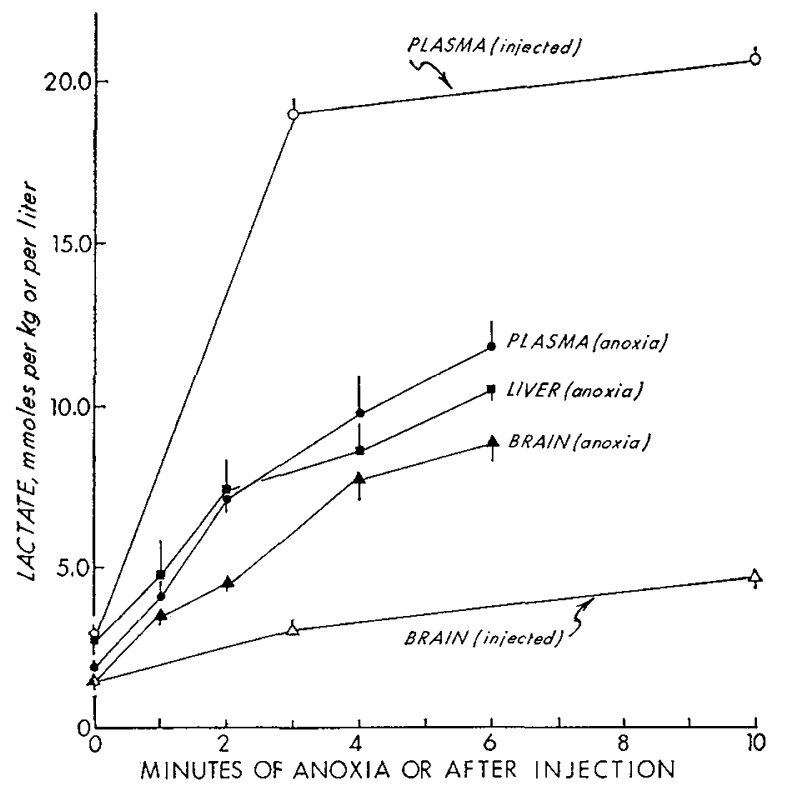

Fig. 3. Permeability of the blood-brain barrier to lactate in newborn mice. Plasma, liver, and brain lactate values of the mice used for Fig. I are also shown (brain and liver lactate levels are from the same animals). Each point is the mean value for three-seven animals. Levels in controls did not change with time and are shown on the ordinate at zero time. 
brain barrier to lactate in the brains of normal newborn mice (Fig. 3). Despite very high plasma lactate values within $3 \mathrm{~min}$ after injection, the increase in brain lactate was small and very slow. Four minutes after injection, when the plasma lactate concentration was raised to twice that seen in the anoxic newborn after an equal interval of anoxia, brain lactate concentration increased only about $1.78 \mathrm{mmol} / \mathrm{kg}$, compared with the increase of $6.22 \mathrm{mmol} / \mathrm{kg}$ during this same interval in the anoxic animals.

\section{Effect of Anoxia on Glucose Levels in Liver and Plasma}

While the brain glucose concentration was falling, hepatic glucose levels increased fourfold. In plasma, glucose increased only twofold (Fig. 1). The explanation for this lack of correspondence of liver and plasma glucose levels during anoxia is not clear. It could be due to a relative failure of hepatic circulation; or, because of the increased demand which is triggered by anoxia, glucose could be removed from the blood by glycolyzing tissues as soon as it is released from the liver. These two possibilities are not mutually exclusive.

\section{Discussion}

It is clear that during anoxia the brain glucose content can be seriously reduced despite normal or even elevated plasma (and liver) glucose levels. What is the mechanism of this paradox? In mice of all ages, from birth [5] through adulthood [9], ischemic anoxia is associated with a striking increase in the rate of cerebral glycolysis. The glucose use rate in the brains of normal newborn mice is $0.07 \mathrm{mmol} / \mathrm{kg} / \mathrm{min}$ [5]. During ischemia induced by decapitation, the glucose use rate is increased 10 -fold [5]. Therefore, in vivo during anoxia, it is quite possible that the demand for glucose by the brain could exceed the supply from the blood. This would be the case with a normal glucose influx, even more so with a reduced cerebral blood supply, and possibly even with an increased but still relatively inadequate glucose supply. The anoxic brain in the intact animal is not a closed system, as demonstrated by the fact that brain lactate accumulated to higher levels than could be accounted for by the disappearance of cerebral glucose and glycogen.

The data support the impression that the increase in brain lactate concentration during anoxia is more likely due to glucose transport and gIycolysis than to transport or diffusion of lactate from plasma to the brain. This is indirect evidence for a maintained circu* lation and transport of glucose from the blood to the brain for anaerobic glycolysis. This conclusion is in accord with the data of Duffy et al. [1], who present evidence that the influx of glucose from blood to brain is indeed increased during hypoxia. Apparently the concentration of glucose in the brain fell in our animals because the increase in the rate of glucose utilization during anoxia was greater than that of glucose transport.

It is of considerable interest that under the circumstances described here (serious reduction of brain glucose in spite of normal or elevated plasma glucose levels) the administration of glucose appears to be of great clinical benefit. A similar paradox of greatly reduced brain glucose content with normal plasma glucose concentration is seen in experimental salicylate poisoning [7]. In this case, concurrent administration of glucose with a toxic dose of salicylate elevated the concentration of glucose in the brain and was associated with a survival of all of the animals compared with a $100 \%$ mortality in littermates who received an equal dose of salicylate without glucose. From the report of Himwich et al. [3], it appears that glucose administration may be equally effective in the maintenance of life during anoxia. These authors observed that after the intraperitoneal injection of glucose the survival time of 8 -day-old rats in an atmosphere of $\mathrm{N}_{2}$ was nearly doubled.

\section{Summary}

In conclusion, blood glucose values are not always proportional to glucose values present in the brain. We have shown that during anoxia increased values of glucose in plasma were associated with profound decreases in the concentration of glucose in the brain. In the practice of clinical medicine, measurements of the concentration of glucose in the blood are frequently made to exclude hypoglycemia as a cause of abnormal central nervous system signs and symptoms. It appears from the present experiments, however, that normal or even elevated glucose levels in the blood cannot be assumed to indicate adequate amounts of glucose in the brain.

\section{References and Notes}

1. Duffy, T. E., Nelson, S. R., And Lowry, O. H.: Cerebral carbohydrate metabolism during acute hypoxia and recovery. J. Neurochem., 19: 959 (1972).

2. Gatfield, P. D., Lowry, O. H., Schulz, D. W., ANd PassonNEAU, J. V.: Regional energy reserves in mouse brain and 
changes with ischaemia and anaesthesia. J. Neurochem., 13: 185 (1966).

3. Himwich, H. E., Bernstein, A. O., Herrlich, H., Chesler, A., AND FazeKas, J. F.: Mechanisms for the maintenance of life in the newborn during anoxia. Amer. J. Physiol., 135: 387 (1942).

4. Holowach-Thunston, J., Fertel, R., Kotler-Brajtburg, J. M., and Matschinsky, F.: Possible causes of hypoglycemia in maple syrup urine disease (Abstract). Society for Pediatric Research, Washington, D.C., 1972, p. 402/142.

5. Holowach-Thurston, J., ANd MCDougal, JR., D. B.: Effect of ischemia on metabolism of the brain of the newborn mouse. Amer. J. Physiol., 216: 348 (1969).

6. Holowhah-Thurston, J., ANd Pierce, R. W.: Increase of glucose and high energy phosphate reserve in the brain after hydrocortisone. J. Neurochem., 16: 107 (1969).

7. Holowach-Thurston, J., Pollock, P. G., Warren, S. K., $\Lambda N D$ JonEs, E. M.: Reduced brain glucose with normal plasma glucose in salicylate poisoning. J. Clin. Invest., 49: 2139 (1970).

8. King, L. J., Lowry, O. H., PassonneaU, J. V., AND Venson, V.:
Effects of convulsants on energy reserves in the cerebral cortex. J. Neurochem., 14: 599 (1967).

9. Lowry, O. H., Passonneau, J. V., Hasselberger, F. X., and Schulz, D. W.: Effect of ischemia on known substrates and cofactors of the glycolytic pathray in brain. J. Biol. Chem., 239: 18 (1964).

10. Mayman, C. J., Gatrield, P. D., and Breckenridge, B. M.: The glucose content of brain in anaesthesia. J. Neurochem., 11: 483 (1964).

11. We thank Dr. David McDougal, Jr., for his many helpful suggestions and review of this manuscript.

12. Presented in part at the Annual Meeting of the Society for Peciatric Research, Washington, D.C., 1972, p. 421/161.

13. This investigation was supported in part by United States Public Health Grant no. NB 06163 and the Allen P. and Josephine B. Green Foundation, Mexico, Missouri.

14. Requests for reprints should be addressed to: JEAN Holowach-Thurston, M.D., Department of Pediatrics, St. Louis Children's Hospital, 500 South Kingshighway, St. Louis, Mo. 63110 (USA).

15. Accepted for publication March 12, 1973. 